\title{
Context and Convergence: Some Remarks on the Law and Society Movement
}

By Lawrence M. Friedman (Marion Rice Kirkwood Professor of Law at Stanford University, Stanford, Ca. USA)

Stanford University, USA

\section{ABSTRACT}

The law and society movement has grown greatly in recent years. It explores two macro-questions: the sources of law, on the one hand, and the impact of law, on the other. It rejects the orthodox view of "legal science", but embraces the methods of the social sciences. My own work has, recently, dealt with the issue of legal impact; and has also delved into socio-legal history. Historical study can act as a kind of control group for law and society studies; comparative and cross - cultural studies can perform the same function. Studies of modern legal system demonstrate a high degree of convergence-in an interconnected world, societies share both problems and solutions. Socio-legal studies themselves have converged; and share a common intellectual language.

Keywords - Human rights, Impact, Socio-legal history, Comparative legal culture, Law and Society movement, Convergence

Disclosure statement - No potential conflict of interest was reported by the author.

License - This work is under Attribution-NonCommercial-ShareAlike 4.0 International (CC BY-NC-SA 4.0) https://creativecommons.org/licenses/by-nc-sa/4.0/

Suggested citation: Friedman, L.M. 2019. "Context and Convergence: Some Remarks on the Law and Society Movement." Law in Context, 36 (1): 12-20. DOI:

https://doi.org/10.26826/law-in-context.v36i1.82

I

It was a pleasure, and an honor, to be asked to contribute to the first issue of the renewed Law in Context. I want to begin by congratulating the scholars who made the rebirth of this journal possible; and extend a hearty welcome to this new member of the family of outlets for studies of law and society. The name of the journal is especially apt. Context is at the heart of law and society studies. Context-that is, the real world. The world where legal systems actually behave; and where people in society experience legal systems, and legal institutions, as part of their lives. Context means to explore what these systems and institutions mean in society; and how societies respond to the work output of legal systems.
The world of law and society scholarship is a big tentsprawling, vivid, colorful, exciting. I think of it as a kind of great academic circus, with thousands of performers, working in every corner of the world; men and women using many different techniques, approaches, strategies; scholars attacking many distinct questions, to which they give distinct answers. The law and society movement is growing, expanding, flexing its muscles; it is already a vital and salient movement; and its future, I think, is extremely bright.

The movement does not have a long history. It has its founding figures: Eugen Ehrlich, for example, and (very 
notably) Max Weber, whose insights are still a valuable part of the canon. As a separate field, an organized field, it is only a few generations old. In the United States, a handful of researchers, mostly sociologists, founded the Law and Society Association (LSA) in the 1950's. Today, a much larger group of scholars identifies with the movement. They are law professors, sociologists, political scientists, anthropologists, historians, economists, and others. The movement has a significant presence in many countries-from Japan to Brazil to Australia to South Africa. LSA itself has grown steadily; and its annual meetings attract thousands of participants. At first, it was strictly an American organization. But it has become distinctly international. Hundreds of its members hail from other countries. LSA has also held annual meetings outside the United States, scheduling these international conferences at roughly four year intervals. LSA has met in Berlin, Budapest, Glasgow, and, most recently, in Mexico City. There are now law and society organizations in Japan, in Australia, in England, in Israel, and elsewhere. The International Sociological Association sponsors a Research Committee on the Sociology of Law, which also holds yearly meetings. All this is encouraging. Of course, if we had our wish, there would be even more of everything: more scholars, more organizations, more studies. But those of us with long memories, who remember the earlier years of law and society scholarship, are grateful for what we have now.

\section{II}

The law and society movement, in essence, looks at legal phenomena with the sharp and objective eyes of the social sciences. It explores, as we said, the way the legal system actually works. This is what binds the membership together; it is what the movement is all about. The movement is also, in a way, against something as well. The enemy-if one may call it that-is conventional legal education and conventional legal scholarship. These embody an old, orthodox approach to law: formalistic, doctrinal, ingrown, conceptual, and strongly normative. This is an approach which dominated, and still dominates, the way law is taught in law faculties, and the way the legal academy writes and thinks about legal issues. The law and society movement has hardly conquered this ancient enemy; but it has seen to it that the old orthodoxy is no longer so absolute and so dominant as it was in the past.

It is, of course, impossible to sum up the work of the law and society movement-what it has accomplished, what insights have come out of the work. Much of the scholarship, however, can be organized around two macroquestions. Conventional legal scholarship mostly ignores these questions; or treats them in the most superficial way. The first question is about the sources of law. What social forces produce specific laws, doctrines, ordinances, regulations; what forces produce patterns of laws, doctrines, ordinances, regulations? What role does public opinion play; or elite opinion; or religion, or science, or recessions and depressions? How does social change alter the mind-set of legal actors, and lead them to change their behavior? The basic assumption underlying this work is that law is not autonomous-that is, independent of society. There is disagreement about whether or not legal institutions can be or are at least slightly autonomous, and to what degree; but total autonomy, no-that is simply impossible. Conventional legal scholarship looks inside the legal system to answer questions of source; it treats law, in short as autonomous. The law and society movement looks outside, and treats the degree of autonomy, if any, as an empirical question.

The second question is about impact. Once a law, doctrine, regulation, institution is in place, what effect does it have? Does it work? Does it induce changes in behavior, and if so, why, and of what sort? Here too the basic assumption is that impact is always an empirical question. There can be no a priori answer to any question of impact. Some laws or doctrines are dead letters; some are effective; most are only partially effective; some are downright counterproductive. There are short term effects, and long-term effects; there are direct effects, and indirect effects. There are positive and negative effects. Some potential burglars give up burglary, because they want to stay out of prison. Other potential burglars react to the law by changing tactics. Skillful burglars drive clumsy ones out of business. Home-owners react to the situation by buying burglar alarms. Other home-owners move to a different city, because they are afraid of burglars in the city they came from. Impact, in short, is complex. And there is no way to know in advance what changes a 
law or decision might bring; what ripples in the stream it might cause. Clearly, though, the study of impact is of the essence. Here too conventional legal scholarship either ignores impact completely; or assumes, without real evidence, that a new rule or decision will accomplish its goal, almost magically.

Law and society scholars also tend to sneer at the very concept of "legal science," the idea that conventional, doctrinal legal studies can be described in any way as "scientific." Law and society scholars do claim for themselves the mantle of science, and they have a right to make this claim-precisely because they reject the idea of "legal science," and instead, turn to established social sciences, and make full use of the tools of sociology, psychology, political science, anthropology, and (yes) economics. The methods are quantitative when that works, qualitative when that works; both, when that seem appropriate. Just as there is a sociology of religion-the external study of religious phenomena-there is also the external study of law and legal systems. Sociology of religion does not ask, which is the true religion. It does not try to solve puzzles of dogma or doctrine within any particular religion. It does not give "right" answers to theological questions. In short, it studies theology as a social phenomenon, but is not in itself theology. Similarly, the social study of law asks questions about the legal system, but does not give answers to legal questions. It is not, in short, a legal theology. Conventional legal scholarship very often is exactly that. To some legal philosophers and jurists there are "correct" answers to legal questions; and lawyers, arguing before a court, will try to persuade the judges that their client's point of view is (legally) "correct." Law and society scholars want to know why a certain answer is considered "correct" in this or that society, at this or that period of time; why an argument today is persuasive, which past generations rejected as total nonsense (a right to gay marriage, for example). But otherwise, they find the question of right answers meaningless.

Of course, we have to be realistic: law and society scholars do have opinions, ideologies, ethical points of view, yes, and even prejudices. These surely make a difference. A scholar is attracted to a certain question because the scholar thinks it is socially important; or simply because the question intrigues and fascinates the scholar; or because the question has a deep personal meaning to the scholar or the scholar's family. Nonetheless, the work is supposed to be rigorous and objective; in theory, opinions and ideologies should have no effect at all on the studies and the finding. But we know that this is, alas, somewhat naïve. The personality and prejudices of the scholar almost inevitably make a difference. In the United States, hundreds of studies have tried to measure whether the death penalty actually has a deterrent effect on crime. If the author is an economist, the answer tends to be yes. If the author is a sociologist, the answer tends to be no. This difference hardly seems accidental.

Still, a good scholar at least tries to follow the rules; tries to stay objective. A good scholar has an open mind-or at least tries to have an open mind. A good scholar is willing to be surprised, disappointed, and even upset at what she finds; and to accept these disappointing results. This means that there is a certain tension between scholarship and advocacy. Advocates-for human rights, say-devote their money, muscles, time, effort, and sometimes their very lives, to causes they believe in. Advocates battle for the environment, gender equality, health and safety, the rights of the underprivileged, the struggle against poverty and oppression. We owe a lot to these advocates; the world would be a much worse place without them. But their zeal makes them, at times, intolerant of scholarship that comes out the wrong way (in their view). In one of my books, The Human Rights Culture, ${ }^{1}$ I tried to discuss the human rights movement in socio-legal terms. Once, giving a talk on this subject, I mentioned, casually, that ideas about human rights were socially and historically contingent. This seems perfectly obvious to me; and would be, I assumed, obvious to everybody else. A few centuries ago, almost nobody-even advanced and elite scholars-would have had the foggiest concept of gender equality, or, for that matter, of gay rights, or the rights of "primitive" and "pagan" people. Yet my audience found what I said to be deeply offensive-they rejected the very idea that there was anything contingent about basic human rights; they reacted with something close to fury. To them,

\footnotetext{
${ }^{1}$ Lawrence M. Friedman, 2011. The Human Rights Culture: A Study in History and Context. New Orleans: Quid Pro Books.
} 
human rights were universal and inherent; and anyone who denied this was (they felt) condoning or indifferent to human suffering.

In a sense, I agree with these critics. I think human rights, in our day, ought to be universal; and I have nothing but admiration for those who work tirelessly to help women, minorities, indigenous people, prisoners, dissenters, refugees, the poor; or who are trying to save our planet from the miseries climate change can bring on. Nonetheless, it is a plain fact that concepts of human rights (and environmental rights) change over time; and from society to society. You are not an enemy of human rights and other good causes, simply because you recognize social and historical facts. And indeed, real scholarship on the politics, economics, history, and sociology of human rights migh turn out in the end to be of real value to the human rights movement. At least I hope so.

\section{III}

The editors of Law in Context invited me to speak about my own work in its pages; and I am happy to add some brief comments about what I have done. Some of my work has been synthetic: attempts to sum up, and make sense of, at least some of the vast body of law and society work. This was so in my recent book, Impact: How Law Affects Behavior. $^{2}$ I had dealt with this issue earlier in my career, in The Legal System: A Social Science Perspective, published in the 1970's. ${ }^{3}$ Impact expanded on the subject, which is one of the two macro-questions in the law and society arsenal, as I mentioned earlier; in this book, I also tried to bring the subject up to date.

I also tried to bring some order into a rather chaotic field. I set out a framework, defined some terms, advanced some basic concepts, and pointed out connections between different types of impact studies. Whether I succeeded, I leave to the reader to judge. In fact, there is a vast literature on impact, effectiveness, obedience and disobedience to law, and a whole cluster of related questions. But scholars in different subareas mostly stayed in their own little province; they talked to other people in their circle, they read each other's works, but ignored what was happening outside of that circle. A great deal has been written, for example, about deterrence, by criminologists, economists, and sociologists. Most American states still have the death penalty (at least formally), and there have been, as I mentioned, countless studies about whether the death penalty has any impact on crime rates, and if so, what the impact might be. There is also an interesting literature on drunk driving: whether campaigns against it, and various punishment regimes, make a difference, and if so when and why and how.

Also: many scholars, particularly political scientists, have been studying business regulation: regulation on air and water pollution, or employment discrimination, or safety and health controls, or stock markets and corporate finance. The question is, when does this regulation work, and when does it fail to work? When is it productive, and when is it counterproductive? What difference do various styles of regulation make? Does harsh enforcement pay off, or do more cooperative and conciliatory methods get better results? This too is impact literature-just as much as studies of the death penalty. Yet, little has been done to work out terms, definitions, theories, and concepts, to tie together the various subareas of impact. I thought it was useful to let the deterrence literature speak to the regulation literature, and vice versa. These are only two examples of research areas that are, in truth, impact research. There are others as well. Does tort litigation in the United States or elsewhere have any effect on the number of auto accidents? What is the best way to make people put on seat belts? Do patent and copyright laws encourage or stifle innovation and creativity? Of course, I have no definitive answers to these hard questions. But I tried, at least in a modest way, to say: here are some ways to analyze and explore impact, here are some terms and concepts that might be useful; here is (maybe) a way to straddle fields which (whether consciously or not) are asking questions about the impact of law.

So much for synthesis. I've also done a good deal of research, both quantitative and qualitative into legal phenomena. Most of it has been historical research. I have spent years digging around in dusty court records, looking

\footnotetext{
${ }^{2}$ Lawrence M. Friedman, 2016. Impact. How Law Affects Behavior. Cambridge, Mass.: Harvard University Press.

${ }^{3}$ Lawrence M. Friedman, 1975. The Legal System: A Social Science Perspective. New York: Russell Sage Foundation.
} 
at old newspapers, and reading statements, books, and papers of dead people, people who lived in the 19th and early 20th centuries. Why was I so focused on history? The most honest answer is because I like it. I do not like interviewing people and doing survey research; or designing experiments, or analyzing big piles of data. These are wonderful things to do, and I admire the people who do them; but they're not for me. I find records of dead people much more congenial.

When I use a term like "historical research", I am referring to socio-legal history. Most of what passes for legal history, in many law faculties, particularly those in Europe, is not "socio-legal" at all. It reflects the same dreary, arid attitude toward law that obsesses law faculties; all it does is add a meaningless time dimension to the conventional approach. "Legal history" then becomes a kind of daisy chain of cases, statutes, doctrines, and treatises, traveling through space and time, almost totally divorced from what was going on in the outside world. There is, of course, a distinction between doctrinal history (useless), and the intellectual history of law and legal ideas, which many of my colleagues, including some I really admire, pay a great deal of attention to. Personally, I am quite skeptical about whether the intellectual history of law and legal systems is valuable, that is, the history of legal ideas and legal philosophy, the work of such jurists as Hans Kelsen or Ronald Dworkin, or H. L. A. Hart. Some of my colleagues consider my attitude misguided. I am not so sure. To me, legal theory, legal ideas, legal philosophies are on the whole effects, not causes; they reflect the age the jurists live in, and are the product of the norms and ideas of their societies. Medieval jurists, however brilliant, reflected medieval society. Modern jurists are no different. And, frankly, in the big world, where real people live and do real things for real reasons, I doubt very much that what my colleague Robert W. Gordon calls "mandarin texts" make much of an impact. If you claim that (say) some branch of legal philosophy, or legal theory, or some book or some philosophical twist or turn, has been quite "influential" (a word whose meaning is extremely vague), I want to see the evidence. I want to see how theory made a difference. I want to see indications of a causal connection between the "mandarin text" and something happening in the real world that reflected the "influence" of the "mandarin text".
Usually, there is no such evidence. But I have to admit mine is a minority view.

Social-legal history is something that appeals to me; something I find extremely exciting. Mucking about in old papers and records provides for me something like the thrill archaeologists must feel, when they dig up the ruins of a buried city, and find long-lost treasures deep below the surface of the earth. To me, there is a romance in old court records, in old newspapers, in the voices of dead people. It is, to use another analogy, like entering a foreign country, like exploring what is in some ways another world. Actually, this world is never entirely foreign, especially if your field (like mine) is not remote legal history, but the legal history of modern times-the legal history of the age that began with the Industrial Revolution. Indeed, one intriguing question, which we have to ask constantly, is this: exactly how foreign is this other world? When you look at an old photograph, the faces are human faces, the clothes are familiar, the landscape is familiar. The photographs tell a story; but there is mystery behind the story, there is something unknown (and possibly unknowable); socio-legal historians try, as best they can, to understand the story, and to solve the mystery.

For me, this is great fun. But I can also honestly defend it as a vital and even necessary branch of law and society research. The past, no matter how foreign, is never totally gone. It casts a shadow. How much of a shadow is the question. And socio-legal history can be immensely rewarding, even when the past fails to cast a shadow: when, instead, it throws into bold relief the fact that the world has changed, that things are very different now, that some feature of the past is in fact dead and buried. The past can act as a kind of control group; it tests the validity of guesses about why things are the way they are. To be sure, people may fall back on history too readily, to explain modern problems and situations. Sometimes this is plausible; often it is not. Violent crime rates are, unfortunately, higher in the United States compared to other developed, western countries. Why is this the case? Is history the key? Is it because of the wild west, the frontier, or the frontier mentality? Some people think so. But it is hard to see why gunfights in Dodge City or Tombstone, Arizona, help explain the murder rate in 
modern Baltimore or Detroit. History is a strong medicine that has to be taken with caution.

Cross-cultural comparisons act as yet another kind of control group. Take the question I just asked: why is violent crime so common in the United States? If we think history is the clue, then consider the violent crime rate in Japan or the United Kingdom. These were both, at one time, violent societies-as violent as the United States, if not more so. But today violent crime rates are much lower than in the United States. Why has their experience been so different? Any explanation of American violence must reckon with the lack of violence in societies that are, in many respects, at a similar stage of social and cultural development.

Another example: in the United States, both law and society have always defined citizens as "black", even if their ancestors were mostly (though not entirely) white. The law has changed; but socially, people who are (say) one-eighth black still consider themselves part of the African-American community; and both whites and nonwhites will classify them this way. During the period of slavery, children of slave mothers were legally slaves. This was true, even if the father was white, which was often the case; white owners and overseers took sexual advantage of slave women, who of course had no say in the matter. As generations passed, many slaves were mostly (genetically) white, and perhaps even looked white. But they were nonetheless still slaves. This attitude, I assumed, persisted even after slavery was abolished.

But is this really what explains racial classification today? I am no longer quite so sure, because the experience in other slave societies-Brazil is the best example-has been strikingly different. In Brazil, many American "blacks" would be simply considered white. Yet slavery itself lasted even longer in Brazil than in the United States. Here is an instance in which cross-cultural research on law complicates in an interesting way an important social and legal phenomenon. There are countless examples where cross-cultural studies act, as in this case, as an important control group.

Cross-cultural studies are also important in and of themselves. We live, after all, in a global village. More and more, socio-legal scholarship pays attention, and must pay attention, to situations, events, problems, and movements that are global or at least trans-national. A glance at law and society journals gives striking proof of this fact: they devote more and more of their pages to studies that are cross-cultural or which reflect, in any event, studies of socio-legal phenomena in Africa, Asia, Europe, Latin America. Take, for example, the second issue of volume 53 of the Law and Society Review. ${ }^{4}$ This journal was once almost exclusively devoted to the United States. But in this issue, which appeared in June 2018, one article is about Russia, a second about Colombia, a third about Egypt, and a fourth about Israel. These essays take up most of the pages of the journal. And this issue is far from exceptional.

A lot of cross-cultural work is at least implicitly comparative. A study might, for example, report data from a country other than the author's own country. Nonetheless, authors and readers might have, at the back of their minds, their own society as a kind of baseline against which to assess the findings. Or they might see the study (of, say, an African society) as a test of some proposition drawn from European societies, or the United States. Many other studies are, in fact, genuinely cross-cultural, looking at more than one legal culture. This kind of work is hard to do well. Conventional legal scholars have it easier. It takes no special skill or training (except for language) to compare some section of the civil code of Argentina with the analogous text in the Finnish or Japanese codes. The essential points are right there on the surface. But getting under the skin of one legal culture is hard enough; doing this for two, or more, is monstrously difficult. Difficult: but worthwhile. If we take findings and ideas developed in Country X, and see if they fit Country Y and Country $\mathrm{Z}$, we can move the whole field of scholarship forward.

Comparative studies often explore differences between legal cultures. Exploring similarities is just as important. A striking feature of modern life and modern culture is convergence: in many ways, developed countries are becoming more and more alike. And this applies to legal systems and legal cultures as well. Right now, it has become a bit harder to recognize convergence, because

\footnotetext{
${ }^{4}$ Cfr. 2019 Law \& Society Review 53 (2, June): 317-634.
} 
(regrettably) there is an upsurge of narrow nationalism, and even xenophobia, all over the planet. Yet convergence is still a dominant aspect of modern social and legal culture. Everywhere in the developed world, people dress the same, the architecture is the same, the music is the same; a drugstore in Tokyo sells much the same line of products as a drugstore in Stockholm. Cars, planes, computers, air conditioners, clocks, microwave ovens: the toys and tools of modernity are the same everywhere.

There are scholars who argue that this is just veneer; that underneath, abiding essences of national cultures persist; that Japan remains uniquely Japan, and is unlike any other society; and we hear over and over again about American exceptionalism (and, less, obviously, about French, or German, or Italian, or Australian exceptionalism as well). Of course, this has at least a grain of truth. No two societies are the same. But, it seems to me, the similarities far outweigh the differences. Similarities in both high and low culture. Nobody is surprised that young Koreans are great at interpreting Mozart and Chopin-or that Korean pop culture is popular far outside Korea. This is a world where ideas and images circle the planet in seconds. It is a world in which countries share a common technology. They also face the same challenges and opportunities-at least in the developed world, and to an extent everywhere else as well. A Frenchman who visits Tokyo, say, will of course notice all sorts of differences between Japan and France. Visitors, however, will simply take for granted the overwhelming similarities, from the moment they land at the international airport.

The law and society movement is, in my view, itself an example of convergence. Imagine an international meeting-of the Research Committee on the Sociology of law, let us say. On one panel, one scholar presents a paper on Canada; other panelists are from Brazil, Poland, and Thailand. The papers, necessarily, will be in English: the participants share no other language. And yet there has to be a common language, one that will work across borders, or such meetings will be quite impossible. For various reasons, the language today happens to be English. Of course, this is a big advantage for native speakers of English. But English is also the working international language of science, business - and of law and society. It is also the international language of air traffic control: if controllers each spoke their native language-and pilots did the same-international airports could hardly function.

There is also a common international language in another sense, a deeper sense. The scholars who present papers at international meetings share something even more fundamental. It is the very fact that they can talk to each other, that they understand the positions, ideas, and ideologies of their fellow panelists; that they share issues, techniques, strategies; that they grasp what fellow scholars are talking about. They can agree or disagree; they can argue and dispute this point or that. But all this takes place within the common language of the discipline. Scientists all over the world-chemists, physicists, medical specialists - also talk to each other in a common language of shared understandings. The same is largely true for scholars in the law and society movement. They are, more and more, international-minded; and, to a large degree, intercultural. But also, and fundamentally, they are able to communicate because they operate within a common cultural world.

Those of us who are part of the law and society movement are proud that we speak this language; proud that we understand this language; proud that we have made at least a small contribution to the development of that language. Many of us have colleagues and former students dotted around the world. They live in different societies; they work on problems, use techniques, and profess points of view which may seem quite alien. But the common language is there, underneath the surface. I hope that I too have made at least a small contribution to the job of constructing that language.

This meta-language includes a shared recognition of the problems which society faces today. If you go back far enough in time, you would find an enormous gap between, say, Japanese legal culture and British legal culture. Today, the two legal systems, and all others, have to deal with common issues, common problems, common situations. I mentioned air traffic control. Jet travel requires air traffic control; and it must be on a more or less uniform basis. Copyright and patent law; the law of international trade; business law issues in general: all modern societies have to deal with these, on both national and international levels. But these are only the most obvious examples. 
Consider, for example, modern family law. This branch of law seems, on the surface, the least amenable to outside influence, the most deeply rooted in tradition and personal choices. Yet family law has changed radically in the last few generations, in country after country. Laws about marriage, divorce, custody, and reproductive rights have been transformed. Modern technology has played a role. The samurai did not worry about in vitro fertilization or surrogate motherhood; nor did citizens of England under Henry VIII. Cultural change has played an even greater role. The history of divorce law is a prime example. What molds divorce law in Chile or Australia seems extremely local; and indeed each society has its own story to tell, and moves at its own pace. Yet the movements have all been more or less in the same direction-all over the world.

The meta-language also includes a shared political culture. This is most obvious in developed countries. It is a culture of democracy and human rights. The club of democracies has grown since the late 20th century. It includes Western Europe, North America, and some of the former Soviet Republics, such as Estonia and Latvia. In Asia, Australia, New Zealand, Japan, South Korea, and Taiwan are thriving democracies; India is democratic, and democracy has gained ground in Indonesia. All of these countries have embraced constitutional regimes; all of them have independent court systems. Almost all of them have given their courts the powerful weapon of judicial review. Moreover, they have signed on to a culture of equality: gender equality, equality for minority groups of all sorts; and they have given courts the power to act as guardians of these rights.

Of course, no country lives up to its constitutional ideals. In every country there are serious shortcomings. And, at this particular point in history-2019-the march toward democracy and the rule of law seems to have stalled in a number of countries; and even gone backwards. Tremendous risks and challenges lie ahead, just over the horizon. A world choking on its own exhaust gases. Rising waters; incredible heat waves; devastating forest fires in California or Sweden; a plague of hurricanes; not to mention political disruptions; and new and more deadly epidemics. Whether present systems can survive, and flourish, and meet these challenges, is an open question.
Democracy and the rule of law require a strong, institutional framework. Institutions do matter. But basically, democracy and the rule of law are matters of custom, tradition, norms: matters in short of culture. Otherwise, they are nothing but words on paper. If the culture is fragile, the framework cannot hold. Conventional legal scholarship has very little to contribute to the study of these challenges-challenges to democracy and the rule of law; or for that matter, climate change, or any other social problems. Serious problems demand serious solutions. And serious solutions require serious research. That research has to be grounded in data, in facts of the real world. It has to be rigorous. Only the law and society movement, only the study of law in context can do the job. Or even try to do the job.

But can the movement succeed at this very difficult job? As we said, thousands of scholars gather every year for annual meetings of law and society organizations. Thousands of papers are presented at these studies. The meetings are awash with data, arguments, findings, conclusions. It is fair to ask, what it all adds up to. What has the field accomplished?

In all honesty, we can make few sweeping generalizations. We can report few major breakthroughs and discoveries. A few scholars have tried to build grand theories; not very successfully (in my opinion). In any event, none of these theories has been widely accepted. Is this a sign of failure? Not really, I would argue. Once we reject the myth of "legal science," we can no longer expect to discover "laws" or regularities, on the model of physics or chemistry; or even on the model of sociology or economics. Legal systems are complexes of human behaviors and attitudes; they differ from period to period, and from culture to culture. Kidneys and livers function much the same for members of a tribe in the Amazon, bankers in London, or for that matter citizens of the Roman Empire or ancient Egypt. But "law" is much more variable. Every society has some way to make rules and enforce them. Scholars might be able to say useful things in general about authoritarian legal systems or democratic ones; about systems in preliterate societies or in ancient kingdoms; or about legal education, or about attempts to reform gender relations; about crime and punishment; about juvenile delinquency; about the 
regulation of stock markets; about the role of copyright and patent law in modern societies; and a thousand other subjects. But not about all of them together.

Researchers can explore various legal worlds with rigor; and (hopefully) come up with insights. To a degree, this has happened, is happening, and will surely continue to happen. Today, we know a lot more than we did about the way concrete legal systems work, and why they work as they do. We know things that might be, can be, and should be, helpful in formulating sound policy-against drunk driving, for example, or ways to make regulation of air pollution work. More of this important work can be expected in the future. Some of it may well appear in the pages of Law in Context. 